\title{
Liquid Volumes from Generalized Cubic Equations of State: Take It with Care
}

\author{
J.O. Valderrama ${ }^{1}$ and M. Alfaro ${ }^{2}$ \\ 1 Faculty of Engineering, Dept. Mechanical Engineering, University of La Serena, Casilla 554, La Serena - Chile \\ 2 Faculty of Sciences, Dept. of Chemistry, University of La Serena, Casilla 554, La Serena - Chile \\ e-mail: jvalderr@elqui.cic.userena.d
}

\begin{abstract}
Résumé - Volumes liquides à partir d'équations d'état cubiques généralisées : à prendre avec précaution - Les volumes en phase liquide de plusieurs fluides importants sur le plan industriel ont été calculés en utilisant sept équations d'état cubiques généralisées. L'équation d'état de Redlich-Kwong et trois de ses formes dérivées, et l'équation d'état de Patel-Teja et deux de ses formes dérivées sont considérées dans cet article.

Les sept équations sont appliquées à 27 fluides, notamment des alcanes, alcènes, composés aromatiques, alcools, éthers, esters, oxydes organiques et composés inorganiques.

Cette étude analyse la précision de ces équations pour prédire les volumes en phase liquide, et donne un certain nombre de recommandations quant à l'équation à utiliser dans une situation donnée.

Mots-clés : volume liquide, masse volumique liquide, équation d'état cubique, corrélations généralisées.

Abstract - Liquid Volumes from Generalized Cubic Equations of State: Take It with Care - Liquid phase volumes of several industrially important fluids have been calculated using seven generalized cubic equations of state. The Redlich-Kwong equation of state and three of its modifications and the Patel-Teja equation of state and two of its modifications are considered in the study.

The seven equations are applied to 27 fluids including alkanes, alkenes, aromatics, alcohols, ethers, esthers, organic oxides and inorganic compounds.

The study analyzes the accuracy of these equations for predicting liquid phase volumes and gives some recommendations on which equation to use for a given situation.

Keywords: liquid volume, liquid density, cubic equations of state, generalized correlations.
\end{abstract}




\section{NOTATION}

\begin{tabular}{|c|c|}
\hline $\begin{array}{l}a_{\mathrm{c}}, b, c, d \\
A, B, C, D\end{array}$ & $\begin{array}{l}\text { parameters in the general EOS } \\
\text { parameters in the EOS }(E q .(4))\end{array}$ \\
\hline$\% \mathrm{D}$ & average percent deviation \\
\hline$\%|\mathrm{D}|$ & absolute average percent deviation \\
\hline GC & Valderrama-Abu-Shark generalized correlation \\
\hline$m$ & parameter in the EOS for $\alpha\left(T_{\mathrm{R}}\right)$ \\
\hline$M$ & molecular weight \\
\hline$N$ & number of data points for each substance \\
\hline$P$ & pressure \\
\hline$P_{\mathrm{c}}$ & critical pressure \\
\hline$P^{\text {cal }}$ & calculated pressure \\
\hline$P^{\exp }$ & experimental pressure \\
\hline PR & Peng-Robinson EOS \\
\hline PT & Patel-Teja EOS \\
\hline PTV & Patel-Teja-Valderrama EOS \\
\hline PTVC & Patel-Teja-Valderrama-Cisternas EOS \\
\hline $\mathrm{R}$ & ideal gas constant \\
\hline RK & Redlich-Kwong EOS \\
\hline SRK & Soave-Redlich-Kwong EOS \\
\hline SVDW & Soave-van der Waals EOS \\
\hline$T$ & temperature \\
\hline$T_{\mathrm{b}}$ & normal boiling temperature \\
\hline$T_{\mathrm{c}}$ & critical temperature \\
\hline$T_{\mathrm{R}}$ & reduced temperature $\left(T / T_{\mathrm{c}}\right)$ \\
\hline$T_{\mathrm{bR}}$ & reduced normal boiling temperature $\left(T_{\mathrm{b}} / T_{\mathrm{c}}\right)$ \\
\hline$V$ & volume \\
\hline$V_{\mathrm{c}}$ & critical volume \\
\hline$V_{\mathrm{L}}$ & liquid volume \\
\hline$Z$ & compressibility factor $(Z=P V / \mathrm{R} T)$ \\
\hline$Z_{\mathrm{c}}$ & critical compressibility factor $\left(Z_{\mathrm{c}}=P V_{\mathrm{c}} / \mathrm{R} T_{\mathrm{c}}\right)$ \\
\hline
\end{tabular}

\section{Greek Letters}

$\alpha \quad$ reduced temperature function in the general EOS

$\omega \quad$ acentric factor

$\Omega_{a}, \Omega_{b}, \Omega_{c}$ parameters in the $a, b, c$ constants of the EOS

\section{INTRODUCTION}

Accurate predictions of liquid volumes are required in many design problems such as condensers and reboilers, the sizing of storage vessels, the calculation of tower heights, material and energy balances involving liquids, and vapor-liquid equilibrium correlation. Although several good empirical and generalized correlations are available for the calculation of saturated liquid volumes (Rackett, 1970; Spencer and Danner, 1972; Shah and Yaws, 1976; Spencer and Adler, 1978; Danner and Daubert, 1983; Campbell and Thodos, 1985; Reid et al., 1987; Valderrama and Abu-Shark, 1989), calculations of saturation properties through equations of state (EOS) present several advantages, specially in simulation of phase equilibrium problems. Liquid volumes also find important uses in nowadays popular modeling of high pressure processes in which the density of the liquid is of importance (Catchpole and von Kamp, 1997).

Common and industrially important EOS are the cubic equations derived from van der Waals EOS. Among the many cubic EOS nowadays available, those of Redlich and Kwong (1949), of Soave (1972), of Peng and Robinson (1976) and of Patel and Teja (1982), among others, have proven to combine the simplicity and accuracy required for the prediction and correlation of volumetric and thermodynamic properties of fluids (Wilson, 1966; Mihajlov et al., 1981; Trebble and Bishnoi, 1986). Non-cubic equations such as the successful EOS proposed by Benedict, Webb and Rubin (1940) are also used in some applications and are included in modern computer simulation programs (Chemstations, 1999).

In some applications, liquid volumes predicted by cubic EOS are corrected using an empirical correction factor. This method gives origin to the translated equation of state, an approach first suggested by Martin (1979) and developed by Peneloux et al. (1982). The concept has been used, with relative success, by several authors to calculate volumetric, thermodynamic and phase equilibrium properties (Jhaveri and Youngren, 1984; Soave and Fredenslund, 1985; Jingshan and Xiaogong, 1986; Watson et al., 1986). Although effective, most of the translated EOS require the calculation of the correction factor from experimental data. Therefore, the translated equations are not of the generalized type of interest in this article.

In this work, seven predictive-type cubic EOS are used for the calculation of saturated liquid volumes of several industrially important fluids, including alkanes, alkenes, aromatics, alcohols, ethers, esthers, organic oxides and inorganic compounds. Calculations are carried out for wide ranges of temperature, from the normal boiling point to near the critical temperature. Calculated values are compared to literature data and conclusions on the accuracy of one or another equations are drawn from the results.

\section{PRESENTATION OF THE EQUATIONS}

The seven generalized EOS analyzed in this work have been well described in the literature. They are: Redlich-Kwong (RK; Redlich and Kwong, 1949), Soave-Redlich-Kwong 
(SRK; Soave, 1972), Soave-van der Waals (SVDW; Soave, 1984), Peng-Robinson (PR; Peng and Robinson, 1976), Patel-Teja (PT; Patel and Teja, 1982), Patel-Teja-VC (PTVC; Valderrama and Cisternas, 1986), and Patel-TejaValderrama (PTV; Valderrama, 1990). All these EOS can be expressed by the following general expression:

$$
P=\frac{\mathrm{R} T}{(V-b)}-\frac{a_{\mathrm{c}} \alpha(T)}{V(V+d)+c(V-d)}
$$

For the RK equation:

$$
\begin{gathered}
a_{\mathrm{c}}=\mathrm{R} T_{\mathrm{c}}^{2.5} / P_{\mathrm{c}} \\
\alpha\left(T_{\mathrm{R}}\right)=\left[1 / T^{0.5}\right]
\end{gathered}
$$

For all the other equations:

$$
\begin{gathered}
a_{\mathrm{c}}=\Omega_{a}\left(\mathrm{R}^{2} T_{\mathrm{c}}^{2} / P_{\mathrm{c}}\right) \\
\alpha\left(T_{\mathrm{R}}\right)=\left[1+m\left(1-T_{\mathrm{R}}^{0.5}\right)\right]^{2}
\end{gathered}
$$

The parameters $c, d, \Omega_{a}$, and $m$ assume different expressions for each EOS as described in Table 1. For computer calculations, the general expression (1) can be written in terms of the compressibility factor $(Z=P V / \mathrm{R} T)$, as follows:

$$
\begin{aligned}
Z^{3} & +(C+D-B-1) Z^{2} \\
& +(A-B D-B C-C-C D-D) Z \\
& +(B C D-A B+C D)=0
\end{aligned}
$$

TABLE 1

Values of $c, d, \Omega_{a}, \Omega_{b}$ and $m$ in the general EOS defined in Eqs. (1)-(3)

\begin{tabular}{l|c|c|c|c|c|c|c}
\hline EOS & $\boldsymbol{d}$ & $\boldsymbol{c}$ & $\Omega_{a}$ & $\Omega_{b}$ & $\Omega_{c}$ & Reference \\
\hline RK & 0 & 0 & 0.42478 & 0.0866 & $* *$ & $* *$ & $\begin{array}{l}\text { Redlich and } \\
\text { Kwong, } 1949\end{array}$ \\
\hline SVDW & 0 & 0 & 0.42188 & 0.1250 & $* *$ & $\begin{array}{l}0.499+1.593 \omega \\
-0.1956 \omega^{2}-0.025 \omega^{3}\end{array}$ & Soave, 1979 \\
\hline SRK & $b$ & 0 & 0.42679 & 0.0865 & $* *$ & $0.480+1.574 \omega-0.176 \omega^{2}$ & Soave, 1972 \\
\hline PR & $b$ & $b$ & 0.45724 & 0.0778 & $* *$ & $0.3746+1.5423 \omega-0.2699 \omega^{2}$ & $\begin{array}{l}\text { Peng and } \\
\text { Robinson, } 1976\end{array}$ \\
\hline PT & $b$ & $c$ & $*$ & $*$ & $*$ & $0.3290+1.3098 \omega-0.2959 \omega^{2}$ & $\begin{array}{l}\text { Patel and Teja, } \\
1982\end{array}$ \\
\hline PTVC & $b$ & $c$ & $-0.210 Z_{c}^{3}+0.00375 Z_{c}^{4}$ & $+0.061 Z_{c}^{2}$ & $0.578-1.904 Z_{c}$ & $-6.608+70.43 Z_{c}-159.0 Z_{c}^{2}$ & $\begin{array}{l}\text { Valderrama and } \\
\text { Cisternas, } 1986\end{array}$ \\
\hline PTV & $b$ & $c$ & $0.6612-0.7616 Z_{c}$ & $0.0221+0.2087 Z_{c}$ & $0.5777-1.8718 Z_{c}$ & $\begin{array}{l}0.4628+3.5823\left(\omega Z_{c}\right) \\
+8.1942\left(\omega Z_{c}\right)^{2}\end{array}$ & $\begin{array}{l}\text { Valderrama, } \\
1990\end{array}$ \\
\hline
\end{tabular}

\footnotetext{
* For the PT equation, the parameters $\Omega_{a}, \Omega_{b}$ and $\Omega_{c}$ assume specific values for each substance. Also, for the PT equation, the expression in terms of the acentric factor for the parameter $m$ is valid for non-polar fluids only.
}

** Those parameters do not exist for the associated equations.

The mean deviations of the values predicted by the EOS were compared to those calculated by a generalized equation from the literature (Valderrama and Abu-Shark, 1989). The generalized correlation gives the liquid volume as a function of the critical properties $\left(P_{\mathrm{c}}, T_{\mathrm{c}}\right.$ and $\left.V_{\mathrm{c}}\right)$ and of the normal boiling temperature $\left(T_{\mathrm{b}}\right)$ :
$V_{\mathrm{L}}=\left(\mathrm{R} T_{\mathrm{c}} / P_{\mathrm{c}}\right)$
$\left[\left(0.3445 P_{\mathrm{c}} / \mathrm{R} T_{\mathrm{c}}\right) V_{\mathrm{c}}^{1.0135}\right]^{\left[1+\left(1-T_{\mathrm{R}}\right)^{2 / 7}\right] /\left[1+\left(1-\mathrm{T}_{\mathrm{bR}}\right)^{2 / 7}\right]}$

In this equation, $\mathrm{R}$ is the ideal gas constant, $T_{\mathrm{R}}$ is the reduced temperature $\left(T_{\mathrm{R}}=T / T_{\mathrm{c}}\right)$, and $T_{\mathrm{bR}}$ is the reduced temperature at the normal boiling point $\left(T_{\mathrm{bR}}=T_{\mathrm{b}} / T_{\mathrm{c}}\right)$. The values of the several properties involved in Equation (6) are shown in Table 2.

\section{RESULTS}

The seven EOS have been used to predict the saturated liquid volume of the 27 selected fluids. Predicted values were compared to data given by Schlunder (1983). The fluids considered in the study and the range of temperature and pressure for the data set are shown in Table 3.

Table 4 shows the average percent deviation and the absolute average percent deviation of the values predicted by 
TABLE 2

Critical and basic properties for all fluids considered in this study.

The data was taken from Reid et al. (1987)

\begin{tabular}{|c|c|c|c|c|c|c|c|}
\hline No. & Fluid & $M$ & $T_{\mathrm{b}}(\mathbf{K})$ & $T_{\mathrm{c}}(\mathrm{K})$ & $P_{\mathrm{c}}(\mathrm{MPa})$ & $Z_{\mathrm{c}}$ & $\omega$ \\
\hline 1 & Methane & 16.04 & 111.7 & 190.6 & 4.60 & 0.288 & 0.008 \\
\hline 2 & Propane & 44.10 & 231.1 & 369.8 & 4.24 & 0.281 & 0.152 \\
\hline 3 & $n$-Hexane & 86.18 & 341.9 & 507.4 & 2.97 & 0.260 & 0.296 \\
\hline 4 & $n$-Decane & 142.29 & 447.3 & 617.6 & 2.11 & 0.247 & 0.490 \\
\hline 5 & Benzene & 78.11 & 353.3 & 562.1 & 4.89 & 0.271 & 0.212 \\
\hline 6 & Toluene & 92.11 & 383.7 & 591.8 & 4.11 & 0.264 & 0.257 \\
\hline 7 & $m$-Xylene & 106.12 & 412.3 & 617.0 & 3.55 & 0.260 & 0.331 \\
\hline 8 & Acetylene & 26.04 & 189.2 & 308.3 & 6.14 & 0.271 & 0.184 \\
\hline 9 & Ethylene & 28.05 & 169.4 & 282.4 & 5.04 & 0.276 & 0.085 \\
\hline 10 & Propylene & 42.08 & 225.4 & 365.0 & 4.62 & 0.275 & 0.148 \\
\hline 11 & Methanol & 32.04 & 337.8 & 512.6 & 8.10 & 0.224 & 0.559 \\
\hline 12 & 1-Propanol & 60.10 & 370.4 & 536.7 & 5.17 & 0.253 & 0.624 \\
\hline 13 & Ethanol & 46.07 & 351.5 & 516.2 & 6.38 & 0.248 & 0.635 \\
\hline 14 & Ethyl Ether & 74.12 & 307.7 & 566.7 & 3.64 & 0.262 & 0.281 \\
\hline 15 & Methyl Tert-Butyl Ether & 88.10 & 331.2 & 503.4 & 3.41 & 0.273 & 0.266 \\
\hline 16 & Ethylene Oxide & 44.05 & 283.5 & 469.0 & 7.19 & 0.258 & 0.200 \\
\hline 17 & Propylene Oxide & 58.08 & 307.5 & 482.2 & 4.92 & 0.228 & 0.269 \\
\hline 18 & Methyl Acetate & 74.08 & 330.1 & 506.8 & 4.69 & 0.254 & 0.324 \\
\hline 19 & Ethyl Acetate & 88.11 & 350.3 & 523.2 & 3.83 & 0.252 & 0.363 \\
\hline 20 & Chloroform & 119.38 & 334.3 & 536.4 & 5.47 & 0.293 & 0.216 \\
\hline 21 & Aniline & 93.13 & 457.5 & 699.0 & 5.31 & 0.242 & 0.382 \\
\hline 22 & Acetic Acid & 60.05 & 391.1 & 594.4 & 5.78 & 0.200 & 0.454 \\
\hline 23 & Acetone & 58.08 & 329.4 & 508.1 & 4.70 & 0.232 & 0.309 \\
\hline 24 & Ammonia & 17.03 & 239.7 & 405.6 & 11.28 & 0.242 & 0.250 \\
\hline 25 & Carbon Dioxide & 44.01 & 194.7 & 304.2 & 7.38 & 0.274 & 0.225 \\
\hline 26 & Carbon Monoxide & 28.01 & 81.70 & 132.9 & 3.50 & 0.295 & 0.049 \\
\hline 27 & Water & 18.02 & 373.2 & 647.3 & 22.50 & 0.229 & 0.344 \\
\hline
\end{tabular}


TABLE 3

Range of temperature and pressure of the literature data (Schlunder, 1983) for the 27 fluids used in this study

\begin{tabular}{|c|c|c|c|}
\hline No. & Fluid & Range of $T(\mathbf{K})$ & Range of $P(\mathbf{M P a})$ \\
\hline 1 & Methane & $111-190$ & $0.1-4.5$ \\
\hline 2 & Propane & $231-367$ & $0.1-4.0$ \\
\hline 3 & $n$-Hexane & $341-507$ & $0.1-3.0$ \\
\hline 4 & $n$-Decane & $447-618$ & $0.1-2.1$ \\
\hline 5 & Benzene & $353-563$ & $0.1-4.9$ \\
\hline 6 & Toluene & $384-594$ & $0.1-4.1$ \\
\hline 7 & $m$-Xylene & $412-617$ & $0.1-3.5$ \\
\hline 8 & Acetylene & 192-309 & $0.1-6.2$ \\
\hline 9 & Ethylene & $169-281$ & $0.1-5.0$ \\
\hline 10 & Propylene & $225-365$ & $0.1-4.6$ \\
\hline 11 & Methanol & $338-512$ & $0.1-7.8$ \\
\hline 12 & 1-Propanol & $373-533$ & $0.1-4.7$ \\
\hline 13 & Ethanol & $351-513$ & $0.1-6.0$ \\
\hline 14 & Ethyl Ether & $308-463$ & $0.1-3.5$ \\
\hline 15 & Methyl Tert-Butyl Ether & $331-503$ & $0.1-3.4$ \\
\hline 16 & Ethylene Oxide & $284-469$ & $0.1-7.2$ \\
\hline 17 & Propylene Oxide & $308-482$ & $0.1-5.0$ \\
\hline 18 & Methyl Acetate & $331-507$ & $0.1-4.7$ \\
\hline 19 & Ethyl Acetate & $350-523$ & $0.1-3.8$ \\
\hline 20 & Chloroform & $335-536$ & $0.1-5.5$ \\
\hline 21 & Aniline & $458-699$ & $0.1-5.3$ \\
\hline 22 & Acetic Acid & $391-595$ & $0.1-5.8$ \\
\hline 23 & Acetone & $329-508$ & $0.1-4.7$ \\
\hline 24 & Ammonia & $240-400$ & $0.1-9.9$ \\
\hline 25 & Carbon Dioxide & $217-304$ & $0.1-7.4$ \\
\hline 26 & Carbon Monoxide & $82-133$ & $0.1-3.5$ \\
\hline 27 & Water & $373-647$ & $0.1-2.2$ \\
\hline
\end{tabular}


TABLE 4

Deviation in saturated liquid volume calculations using several EOS.

The values are percent deviation defined by Eq. (6).

GC corresponds to the deviations given by a generalized correlation given by Eq. (5)

\begin{tabular}{|c|c|c|c|c|c|c|c|c|c|}
\hline No. & Fluid & RK & SVDW & SRK & PR & PT & PTVC & PTV & GC \\
\hline 1 & Methane & 7.6 & -38.7 & -8.6 & -0.5 & -12.0 & -8.9 & -0.9 & 3.6 \\
\hline 2 & Propane & -21.8 & -40.1 & 11.5 & 2.6 & -3.7 & -6.6 & -2.3 & 0.9 \\
\hline 3 & $n$-Hexane & -19.7 & -46.6 & -14.8 & -15.9 & -2.8 & -0.1 & 2.4 & 1.2 \\
\hline 4 & $n$-Decane & 5.2 & -51.2 & -19.7 & -6.7 & 0.1 & -27.8 & 3.4 & 0.9 \\
\hline 5 & Benzene & -13.8 & -44.4 & -14.2 & -0.3 & -2.6 & -1.1 & -4.9 & 0.9 \\
\hline 6 & Toluene & -9.1 & -49.0 & -12.3 & -5.3 & -4.4 & -2.2 & 0.8 & 0.9 \\
\hline 7 & $m$-Xylene & -22.4 & -48.9 & -17.3 & -7.6 & -2.5 & -1.2 & 1.7 & 1.9 \\
\hline 8 & Acetylene & -10.5 & -40.2 & -8.9 & -0.8 & -0.7 & 5.1 & 3.9 & 3.6 \\
\hline 9 & Ethylene & -8.8 & -40.0 & -7.9 & 2.5 & -3.4 & 2.6 & -8.5 & 3.7 \\
\hline 10 & Propylene & -13.6 & -14.7 & -8.9 & -3.6 & -5.7 & 3.1 & -1.5 & 2.8 \\
\hline 11 & Methanol & -57.8 & -81.5 & -41.0 & -25.5 & -12.1 & 2.1 & -7.4 & 4.3 \\
\hline 12 & 1-Propanol & -47.2 & -69.9 & -36.8 & 16.4 & -3.1 & -37.8 & -6.4 & 1.0 \\
\hline 13 & Ethanol & -23.8 & -63.7 & -29.9 & -16.1 & -5.5 & -15.5 & -7.2 & 3.6 \\
\hline 14 & Ethyl Ether & -24.0 & -50.9 & -18.8 & -4.9 & 2.5 & -1.0 & -1.3 & 1.8 \\
\hline 15 & Methyl Tert-Butyl Ether & -17.2 & -45.6 & -12.6 & -3.3 & 2.1 & 2.5 & 4.6 & 2.1 \\
\hline 16 & Ethylene Oxide & -20.4 & -50.9 & -18.7 & -8.0 & 11.3 & -2.1 & -0.5 & 3.9 \\
\hline 17 & Propylene Oxide & -32.1 & -64.1 & -13.3 & -29.1 & -16.0 & 0.7 & 1.8 & 4.9 \\
\hline 18 & Methyl Acetate & -23.9 & -53.9 & -28.7 & -18.1 & -5.8 & -1.9 & 1.0 & 2.8 \\
\hline 19 & Ethyl Acetate & -24.7 & -54.2 & -19.3 & -9.5 & 9.5 & -1.7 & 0.9 & 0.6 \\
\hline 20 & Chloroform & -10.0 & -35.0 & -6.4 & 3.0 & 2.2 & -8.1 & -6.3 & 4.9 \\
\hline 21 & Aniline & -21.3 & -45.8 & -16.8 & -7.1 & -1.4 & 1.1 & 5.7 & 4.2 \\
\hline 22 & Acetic Acid & -35.7 & -62.2 & -17.2 & -16.6 & -9.8 & 8.2 & 11.0 & 2.7 \\
\hline 23 & Acetone & -30.0 & -63.2 & -26.3 & -15.7 & -12.5 & 0.4 & 2.3 & 0.9 \\
\hline 24 & Ammonia & -40.3 & -67.4 & -31.0 & -16.1 & -17.7 & -3.3 & -13.9 & 4.1 \\
\hline 25 & Carbon Dioxide & -15.9 & -41.1 & 8.9 & -1.0 & -2.5 & -3.2 & -0.2 & 2.5 \\
\hline 26 & Carbon Monoxide & -2.8 & -31.3 & -3.3 & 6.7 & 1.0 & -3.7 & -3.7 & 4.5 \\
\hline \multirow[t]{3}{*}{27} & Water & -39.6 & -76.5 & -33.0 & -22.5 & 3.9 & -4.6 & -2.2 & 5.0 \\
\hline & $\% \mathrm{D}$ & -22.2 & -52.3 & -16.5 & -7.5 & 3.4 & 3.9 & 1.0 & 2.7 \\
\hline & $\%|D|$ & 22.1 & 52.3 & 18.0 & 8.6 & 9.8 & 5.8 & 3.9 & 2.7 \\
\hline
\end{tabular}


TABLE 5

Deviation in saturated liquid volume calculations near the critical point $\left(T_{\mathrm{R}}>0.9\right)$.

The deviations are defined by Eq. (7)

\begin{tabular}{|c|c|c|c|c|c|c|c|c|}
\hline No. & Fluid & RK & SVDW & SRK & PR & PT & PTVC & PTV \\
\hline 1 & Methane & -20.2 & -41.4 & -20.1 & -14.0 & -32.7 & -29.5 & -11.1 \\
\hline 2 & Propane & -44.6 & -46.7 & -22.4 & -5.7 & -14.6 & -15.8 & -13.0 \\
\hline 3 & $n$-Hexane & -20.5 & -42.6 & -10.1 & -27.5 & -7.0 & -5.3 & 1.5 \\
\hline 4 & $n$-Decane & 9.6 & -55.0 & -24.7 & -6.9 & -0.8 & -21.8 & 0.3 \\
\hline 5 & Benzene & -17.7 & -40.0 & -24.2 & -3.7 & -8.0 & -7.1 & -1.2 \\
\hline 6 & Toluene & 0.7 & -44.4 & -15.3 & -11.5 & -9.8 & -8 & -1.4 \\
\hline 7 & $m$-Xylene & -25.0 & -46.3 & -21.8 & -13.9 & -9.3 & -8.8 & -1.6 \\
\hline 8 & Acetylene & -14.8 & -35.5 & -14.3 & -5.4 & -6.7 & 3.4 & 1.2 \\
\hline 9 & Ethylene & -19.3 & -42.9 & -17.8 & -5.4 & -12.9 & -6.5 & -6.6 \\
\hline 10 & Propylene & -27.0 & 12.8 & -26.9 & -14.2 & -20.1 & -18 & -13.7 \\
\hline 11 & Methanol & -74.5 & -86.5 & -48.2 & -32.7 & -23.7 & -15.7 & -12.7 \\
\hline 12 & 1-Propanol & -76.5 & -93.3 & -66.2 & 64.6 & -16.5 & -91.5 & -17.9 \\
\hline 13 & Ethanol & -82.9 & -75.3 & -46.1 & -30.4 & -18.8 & -27.3 & -19.5 \\
\hline 14 & Ethyl Ether & -31.4 & -50.7 & -24.7 & -11.3 & -12.2 & -8.9 & -8.8 \\
\hline 15 & Methyl Tert-Butyl Ether & -19.8 & -42.5 & -17.2 & -10.7 & -5.3 & -5.3 & 0.9 \\
\hline 16 & Ethylene Oxide & -23.1 & -48.4 & -22.5 & -13.8 & 38.1 & -7.4 & -1.3 \\
\hline 17 & Propylene Oxide & -37.1 & -63.0 & -35.0 & -34.7 & -23.3 & -8.2 & -1.2 \\
\hline 18 & Methyl Acetate & -28.0 & -50.5 & -28.6 & -18.6 & -12.3 & -9.2 & -0.6 \\
\hline 19 & Ethyl Acetate & -29.1 & -50.4 & -25.2 & -15.7 & -24.5 & -9.1 & -1.5 \\
\hline 20 & Chloroform & -27.1 & -32.0 & -9.1 & -1.7 & -0.8 & -10.4 & -15.2 \\
\hline 21 & Aniline & -26.5 & -47.7 & -26.8 & -17.7 & -9.4 & -13.0 & 2.3 \\
\hline 22 & Acetic Acid & -60.5 & -87.3 & -30.0 & -43.9 & -34.8 & -15.5 & -7.7 \\
\hline 23 & Acetone & -33.5 & -58.6 & -31.0 & -22.7 & -10.4 & -6.7 & 0.5 \\
\hline 24 & Ammonia & -48.9 & -69.1 & -38.4 & -23.3 & -25.5 & -8.6 & -31.4 \\
\hline 25 & Carbon Dioxide & -17.9 & -8.1 & -38.2 & 36.8 & -7.1 & -7.2 & -2.1 \\
\hline 26 & Carbon Monoxide & -5.5 & -28.3 & -6.5 & 0.9 & -1.3 & -6.5 & -13.5 \\
\hline \multirow[t]{3}{*}{27} & Water & -41.4 & -68.1 & -38.1 & -28.1 & 32.0 & -11.5 & -4.2 \\
\hline & $\% \mathrm{D}$ & -31.2 & -50.7 & -26.1 & -16.3 & -12.7 & -13.5 & -6.6 \\
\hline & $\%|\mathrm{D}|$ & 32.0 & 51.7 & 26.1 & 19.1 & 17.8 & 13.8 & 6.9 \\
\hline
\end{tabular}




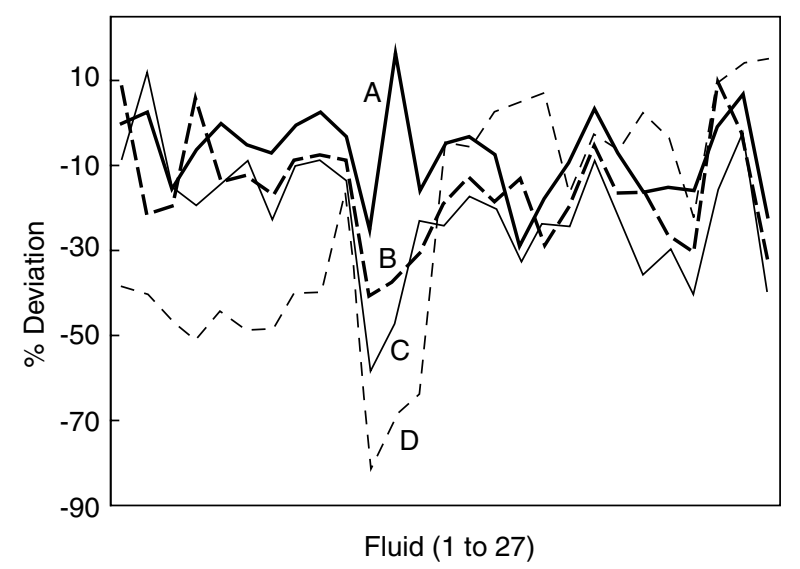

Figure 1

Mean deviation in saturated liquid volumes predicted by four two-parameter EOS: PR (A), SRK (B), RK (C), and SVDW (D).

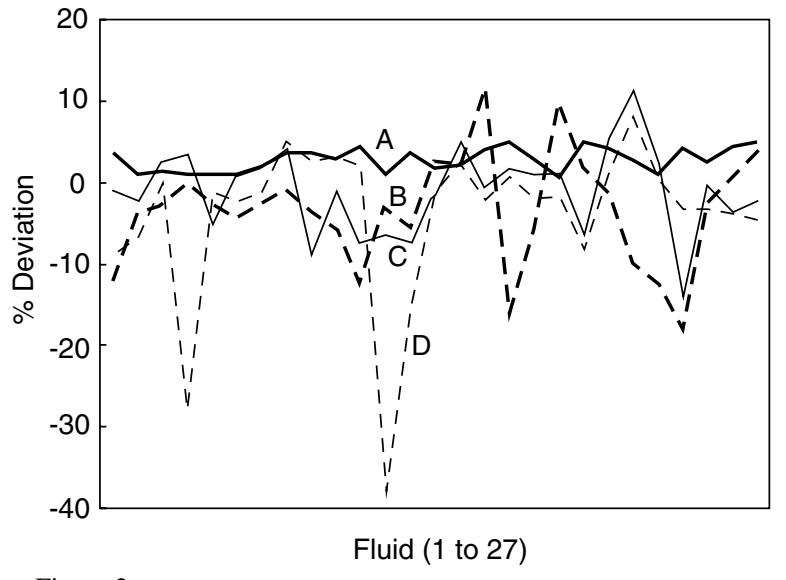

Figure 2

Mean deviation in saturated liquid volumes predicted by a generalized correlation (A) and three three-parameter EOS: PT (B), PTV (C), and PTVC (D). all the EOS used in this work. The average percent deviation $(\% \mathrm{D})$, and the absolute average deviation $(\%|\mathrm{D}|)$, for a set of $N$ values, are defined as follows:

$$
\begin{aligned}
& \% \mathrm{D}=(100 / N) \Sigma\left[\left(P_{\text {calc }}-P_{\text {exp }}\right) / P_{\text {exp }}\right]_{i} \\
& \%|\mathrm{D}|=(100 / N) \Sigma\left|\left[\left(P_{\text {calc }}-P_{\text {exp }}\right) / P_{\text {exp }}\right]_{i}\right|
\end{aligned}
$$

Table 5 shows the deviations in predicting the volumes near the critical point, a region where most EOS give higher deviations. Figures 1 and 2 summarize all the results for the 27 fluids considered in this work.

\section{DISCUSSION}

The old and popular RK equation has no adjustable parameters and gives poor results. The SVDW equation, a generalization of the van der Waals equation proposed by Soave (1984), gives the worst results. This is understandable because of the known inaccuracies of the van der Waals equation, despite its tremendous importance in the development of EOS. The popular SRK and PR equations, of extensive application in fluid phase equilibrium calculations, do not satisfy the minimum accuracy required for some applications. As seen in Table 4, deviations go to $36 \%$ for SRK and to $29 \%$ for PR for some fluids.

The three-parameter equations (PT, PTVC, and PTV) give the best results. The PT equation uses the acentric factor as generalizing parameter, the PTVC uses the critical compressibility factor, and the PTV uses both the critical compressibility factor and the acentric factor. The convenience of using these two parameters has been explained in the literature (Valderrama and Cisternas, 1987), and the reasons given by the authors seem to be justified.
The PTV EOS gives the best results of the seven equations evaluated in this study. However, even the accuracy of this equation is lower than good generalized correlations available in the literature, deviations higher than $10 \%$ are found for some fluids. As shown in Table 4, good generalized correlations found in the literature give deviations below $5 \%$ for all types of fluids (Valderrama and Abu-Shark, 1989).

All the EOS give higher deviations near the critical point, specially the two-parameter equations. This fact is expected of any cubic equation which predicts a unique critical compressibility factor $\left(Z_{c}\right)$, to fulfill the property of continuity of the critical isotherm at the critical point. That is, when the mathematical condition $(\partial P / \partial V)_{T}=\left(\partial^{2} P / \partial V^{2}\right)_{T}=0$ is applied at the critical point. The SVDW gives $Z_{\mathrm{c}}=0.375$, the RK and the SRK give $Z_{\mathrm{c}}=0.333$, and the PR equation gives $Z_{\mathrm{c}}=0.307$. Table 2 shows the actual values of $Z_{\mathrm{c}}$, which vary from 0.2 to 0.3 .

\section{CONCLUSIONS AND RECOMMENDATIONS}

The cubic equations of state used have shown to predict liquid volumes with varying degrees of accuracy, accuracy which increases as the complexity of the equation increases. If accurate values of liquid densities are needed, equations of state are not the best way to go. Based on this study and information from the literature, the following recommendations can be given for the estimation of liquid volumes:

- do not use old equations of state, although they appear to be popular and still in use. They are not good for liquid density estimations;

- if equations of state are to be used, prefer a threeparameter equation such as PT or PTV; 
- always prefer generalized semi-empirical correlations such as those proposed in the literature (Valderrama and Abu-Shark, 1989);

- for some heavy and complex fluids (such as decane, propanol, ammonia or chloroform), even the use of the best equation of state or a good generalized correlation does not guarantee high accuracy;

- a general statement about the accuracy of one or another equation or correlation cannot be done. Thus, liquid density estimation, especially through equations of state, should be taken with care.

\section{ACKNOWLEDGMENTS}

The authors thank the Dirección de Investigación of the University of La Serena, for its support through the research grant DIULS 220-2-31, the Fundación Andes for its grant C-13398/6 (1998-2000), and the Centro de Información Tecnológica (CIT/Casilla 554/La Serena-Chile), for computer support.

\section{REFERENCES}

Benedict, M., Webb, G.B. and Rubin, L.C. (1940) An Empirical Equation for Thermodynamic Properties of Light Hydrocarbons and their Mixtures. Chem. Eng. Progress, 47, 11, 571-578.

Campbell, S.W. and Thodos, G. (1985) Prediction of Saturated Liquid Densities and Critical Volumes for Polar and Nonpolar Substances. J. Chem. Eng. Data, 30, 102-111.

Catchpole, O.J. and von Kamp, J.C. (1997) Phase Equilibrium for the Extraction of Squalene from Shark Liver Oil using Supercritical Carbon Dioxide. Ind. Eng. Chem. Res., 36, 37623768.

Chemstations (1999) Process Flowsheet Simulator, ChemCAD III, Chemstations Inc., 2901 Wilcrest Dr., Suite 305, Houston, TX.

Danner, R.P. and Daubert, T.E. (1983) Chap. 4, in Manual for Predicting Chemical Process Design Data, AIChE, New York.

Jhaveri, B.S. and Youngren, G.K. (1984) Three Parameter Modification of the Peng-Robinson Equation of State to Improve Volumetric Predictions. 59th Annual Technical Conference and Exhibition, Houston, Sept. 16-19, SPE 13118.

Jingshan, T. and Xiaogong, W. (1986) The Equation of State Capable of Representing PVT Behavior of Saturated Vapor and Liquid. Proc. of the National Engineering Thermodynamic Conference, Beijing, 10, 21, 137-142 (in Chinese).

Martin, J.J. (1979) Cubic Equations of State-Which? Ind. Eng. Chem. Fundam., 18, 2, 81-97.

Mathias, P.M., Naheiri, T. and Oh, E.M. (1989) A Density Correction for the Peng Robinson Equation of State. Fluid Phase Equil., 47, 77-87.

Mihajlov, A., Djordjevic, B. and Tasic, A. (1981) Calculation of Enthalpy and Entropy of Gases by Modified R.K. Equation of State. Hungarian J. of Ind. Chem., 9, 407-416.
Patel, N.C. and Teja, A.S. (1982) A New Cubic Equation of State for Fluids and Fluid Mixtures. Chem. Eng. Sci., 37, 3, 463-473.

Peneloux, A., Rauzy, E. and Freze, R. (1982) A Consistent Correction for Redlich-Kwong-Soave Volumes. Fluid Phase Equil., 8, 7-23.

Peng, D.Y. and Robinson, D.B. (1976) A New Two-Constant Equation of State. Ind. Eng. Chem. Fundam., 15, 1, 59-64.

Rackett, H.G. (1970) Equation of State for Saturated Liquids. J. Chem. Eng. Data, 15, 4, 514-517.

Redlich, O. and Kwong, J.N.S. (1949) On the Thermodynamics of Solutions. V. An Equation of State. Fugacities of Gaseous Solutions. Chem. Rev., 44, 2, 233-244.

Reid, R.C., Prausnitz, J.M. and Poling, B.E. (1987) The Properties of Gases and Liquids, McGraw-Hill Book Co., New York.

Schlunder, E.U. (ed.) (1983) Heat Exchanger Design Handbook, Vol. 5., Hemisphere Pub. Corp., New York.

Shah, P.N. and Yaws, C.L. (1976) Densities of Liquids. Chem. Eng., Oct. 25 (taken from Yaws, 1977).

Soave, G. (1972) Equilibrium Constants from a Modified Redlich-Kwong Equation of State. Chem. Eng. Sci., 27, 11971203.

Soave, G. (1984) Improvement of the van der Waals Equation of State. Chem. Eng., Sci., 39, 2, 357-369.

Soave, G. and Fredenslund, A. (1985) Development of an Equation of State Group Contribution Based Method. 8th Seminar on Applied Thermodynamics, Trieste.

Spencer, C.F. and Adler, S.B. (1978) A Critical Review of Equations for Predicting Saturated Liquid Density. J. Chem. Eng. Data, 23, 1, 82-89.

Spencer, C.F. and Danner, R.P. (1972) Improved Equation for Prediction of Saturated Liquid Density. J. Chem. Eng. Data, 17, 236-241.

Trebble, M.A. and Bishnoi, P.R. (1986) Accuracy and Consistency Comparisons of Ten Cubic Equations of State for Polar and NonPolar Compounds. Fluid Phase Equil., 29, 465-474.

Valderrama, J.O. (1990) A Generalized Patel-Teja Equation of State for Polar and Nonpolar Fluids and Mixtures. J. Chem. Eng. Japan, 23, 1, 87-91.

Valderrama, J.O and Abu-Shark, B. (1989) Generalized Correlations for the Calculation of Density of Saturated Liquids and Petroleum Fractions. Fluid Phase Equil., 51, 87-100.

Valderrama, J.O. and Cisternas, L.A. (1986) A Cubic Equation of State for Polar and Other Complex Mixtures. Fluid Phase Equil., 29, 431-438.

Valderrama, J.O. and Cisternas, L.A. (1987) On the Choice of a Third (and Fourth) Generalizing Parameters for Equations of State. Chem. Eng. Sci., 42, 12, 2957-2961.

Wilson, G.M. (1966) Calculation of Enthalpy Data from a Modified Redlich-Kwong Equation of State. Adv. Cryog. Eng., 11, 392-400.

Watson, P., Cascella, M., Salerno, S. and Tassios, D. (1986) Prediction of Vapor Pressures and Saturated Volumes with a Simple Cubic Equation of State: Part II: The van der Waals-711 EOS. Fluid Phase Equil., 27, 35-52.

Yaws, C.L. (1977) Physical Properties, McGraw-Hill, New York.

Final manuscript received in August 2000 